\title{
Surgical Outcomes of Sphenoid Wing Meningioma with Periorbital Invasion
}

\author{
Ga-On Park, ${ }^{1}$ Hyun Ho Park, Jihwan Yoo, ${ }^{1}$ Chang-Ki Hong, ${ }^{2}$ Jiwoong $0 \mathrm{~h}^{3}$ \\ Department of Neurosurgery, Gangnam Severance Hospital, Yonsei University, Seoul, Korea \\ Department of Neurosurgery, ${ }^{2}$ Asan Medical Center, University of Ulsan College of Medicine, Seoul, Korea \\ Department of Neurosurgery, ${ }^{3}$ Severance Hospital, Yonsei University, Seoul, Korea
}

Objective : The aim of this study was to evaluate the clinical outcome of sphenoid wing meningioma with periorbital invasion (PI) after operation.

Methods : Sixty one patients with sphenoid wing meningioma were enrolled in this study. Their clinical conditions were monitored after the operation and followed up more than 5 years at the outpatient clinic of a single institution. Clinical and radiologic information of the patients were all recorded including the following parameters : presence of Pl, presence of peri-tumor structure invasion, pathologic grade, extents of resection, presence of hyperostosis, exophthalmos index (El), and surgical complications. We compared the above clinical parameters of the patients with sphenoid wing meningioma in the presence or absence of PI (non-PI), then linked the analyzed data with the clinical outcome of the patients.

Results : Of 61 cases, there were $14 \mathrm{PI}$ and 47 non-PI patients. PI group showed a significantly higher score of El $(1.37 \pm 0.24 \mathrm{vs.}$ $1.00 \pm 0.01, p<0.001)$, more frequent presence of hyperostosis ( $85.7 \%$ vs. $14.3 \%, p<0.001)$, and lower rate of gross total resection (GTR) $(35.7 \%$ vs. $68.1 \%, p=0.032)$. The lower score of pre-operative $\mathrm{El}$, the absence of both Pl and hyperostosis, smaller tumor size, and the performance of GTR were associated with lower recurrence rates in the univariate analysis. However, in the multivariate analysis, the performance of GTR was the only significant factor to determine the recurrence rate $(p=0.043)$. The incidences of surgical complications were not statistically different between the subtotal resection (STR) and GTR groups, but it was strongly associated tumor size $(p=0.017)$.

Conclusion : The GTR group showed lower recurrence rate than the STR group without differences in the surgical complications. Therefore, the GTR is strongly recommended to treat sphenoid wing meningioma with PI for the better clinical outcome.

Key Words : Meningioma · Sphenoid bone · Orbit · Hyperostosis · Neurosurgical procedures · Treatment outcome.

\section{INTRODUCTION}

Unlike other neurosurgical tumors, even the experienced surgeons often encounter a dilemma during the planning pro- cess of treating sphenoid wing meningioma with periorbital invasion (PI). Firstly, these tumors are not found frequently, and they are somewhat anatomically unfamiliar due to the nature of tumor mass concealed deep in the skull base. Theo-

- Received : April 28, 2021 •Revised : July 19, 2021 •Accepted : August 17, 2021

- Address for reprints : Jiwoong Oh

Department of Neurosurgery, Yonsei University College of Medicine, 50-1 Yonsei-ro, Seodaemun-gu, Seoul 03722, Korea

Tel : + 82-2-2228-6500, Fax : +82-2-393-9979, E-mail : nsojw@yuhs.ac, ORCID : https://orcid.org/0000-0001-6065-4821

This is an Open Access article distributed under the terms of the Creative Commons Attribution Non-Commercial License (http://creativecommons.org/licenses/by-nc/4.0) which permits unrestricted non-commercial use, distribution, and reproduction in any medium, provided the original work is properly cited. 
retically, the maximal removal of tumor as well as the lesions of PI with hyperostosis is ideal. However, an aggressive extent of operation may cost many surgical complications such as visual disturbance or proptosis of the eye ipsilaterally located to the tumor mass. Evidently, the anatomical structures in the proximity of the tumor mass are complex, and the eloquent regions around the tumor are susceptible to the injury during the operation. In addition, experienced surgical skills are often required to manage the periorbital fat, bony gliding of the hyperostosis site followed by careful periorbital reconstruction. In the real practice, the treatment options for the sphenoidal meningioma with PI depend on the surgeon's personal training, experience and surgical preference, and surgery is not always recommended to every patient. Ringel et al. ${ }^{13)}$ reported that the prognosis is good even if the remnant is present without radical resection, and that the surgical aim should be symptom relief rather than radical resection. On the other hand, Mariniello et al. ${ }^{10)}$ reported that recurrence rate of the tumor depended on the extent of resection. To our best knowledge, the comparative analyses of surgical outcomes based on the extent of resection in treating sphenoid wing meningioma with PI are not many. According to the report of Kiyofuji et al. ${ }^{8)}$ in 2020, there were $20-40 \%$ rates of complications occurred in the patients with aggressive removals of sphenoorbial meningioma, but they did not include the PI to further analyze the patient data. Samadian et al. ${ }^{15)}$ also performed a clinical study on the 57 patients with sphenoorbital enplaque meningioma, but they did not analyze the significance of the presence of PI even though they reported that there were 16\% incidence rates of PI occurred in the patients. As the recent studies also implied, there is yet no general agreement on the surgical methods of radial and safe resections of the tumor based on the presence of $\mathrm{PI}^{4,11,12,16,17)}$.

We hereby showed a single institutional study of the surgical cases of sphenoid wing meningioma with PI analyzed with multiple clinical factors to evaluate the final clinical outcome of the patients.

\section{MATERIALS AND METHODS}

This study is retrospective study of a single institution based on electronic medical record chart review and does not require Institutional Review Board's approval. Sixty one patients with sphenoid wing meningioma were enrolled in this study. They were followed up for more than 5 years post-operatively from 2010 to 2014. All the enrolled patients were divided into two groups based on the presence or absence of PI. All data was obtained through the radiologic findings and the electronic medical database of Gangnam Severance Hospital. Data collected included the following main information : basic demographics of patients with radiologic findings; extent of resection; hyperostosis; presence of tumor recurrence event; operation time; amount of intraoperative bleeding; pre-operative symptoms; changes in the pre-operative and post-operative exophthalmos index (EI); clinical outcomes; and surgical complications. Clinical factors to evaluate and define surgical difficulties were the amount of intraoperative bleeding and operation time. The surgical complications were divided into early and late in terms of time of the events. "Early" complications were defined as the onset of abnormal symptoms reported within 2 weeks after the operation and this was usually found while the patient was hospitalized. "Late" complications were defined as the surgical complications reported during the follow-up period at the outpatient clinic, usually 1 or 2

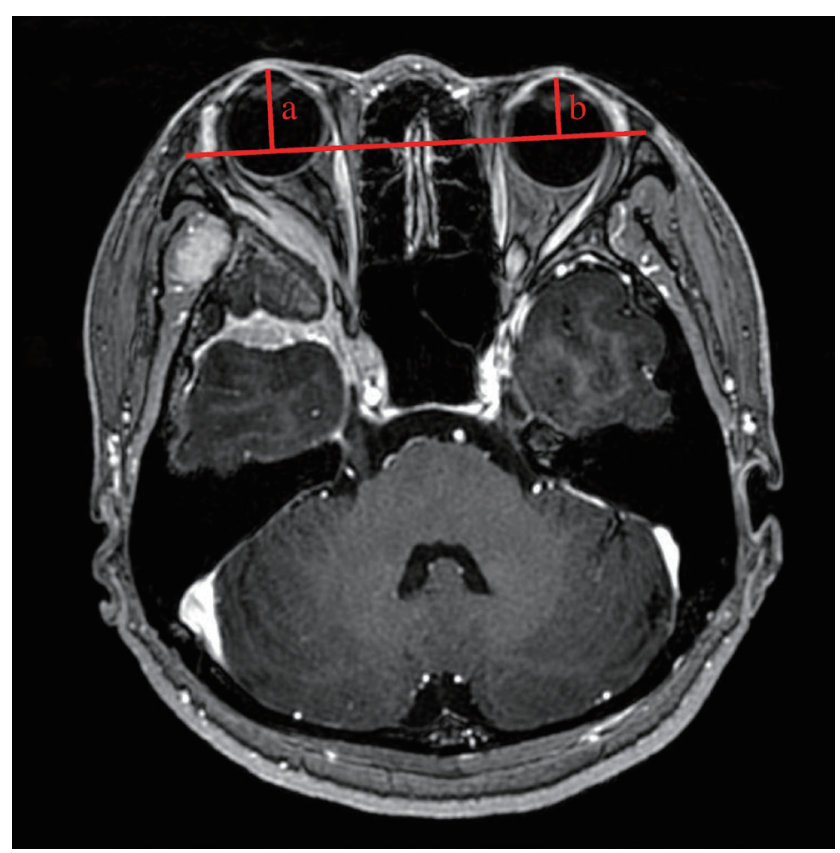

Fig. 1. Definition of exophthalmos index (EI). EI=a/b. The length of perpendicular line from the base line connecting the bilateral zygomatic bones to the most anterior point of the orbital globe is measured for both eyes. The ratio of the length (a) of the ipsilateral side of the tumor over the length (b) of the contralateral side of the tumor were calculated as El score. 
years after discharging from the hospital. We applied the method of measuring EI reported by Scarone et al. ${ }^{16}$. The EI was defined as marked in Fig. 1. All patients underwent brain computed tomography (CT) scans immediately after the initial surgery as a routine protocol, and the post-operative brain magnetic resonance imaging (MRI) was performed within 1 week after the operation. Based on the official radiologic readings, the extent of resection was classified into gross total resection (GTR) and subtotal resection (STR). The criteria for GTR were defined to include the removal of all mass lesions of tumor as well as the removal of invaded orbital components in the presence of periorbital lesions. In cases of hyperostosis, GTR was confirmed when the hyperostosis site was sufficiently drilled out. The GTR was defined as macroscopically complete tumor resection with the removal of affected dura and underlying bone (Simpson grade 1). STR was defined when the periorbital tumor components or the lesions of hyperostosis were still present after the operation. Recurrence was defined based on the official radiologic reading confirmed in the follow-up brain MRI. The routine follow-up MRI was performed 6 months after the operation. Then, the MRI was performed every 1 or 2 years at the outpatient clinic. Radiotherapy was performed at the time of diagnosing recurrence of tumor. However, in the recurred cases with pathological World Health Organization grade 1, radiotherapy was not performed immediately even if the incomplete resection of the tumor was noted during the follow-up.

\section{Statistical analysis}

All studies were statistically analyzed using IBM SPSS version 23 (IBM Corp., Armonk, NY, USA). The continuous variables were presented as the means and standard deviations, whereas the categorical variables were presented as frequencies and percentages. An independent t-test was used to compare the continuous variables of the two groups. A chisquare test was used to compare the nominal factors of the two groups. The statistical significance was confirmed when the $p$-value was $<0.05$. The distribution of continuous variables was tested using Kolmogorov-Smirnov and Levene's tests. Logistic regression analysis was used to identify the surgical factors to predict recurrence and complication results. Then, the results were expressed as odds ratio with $95 \%$ confidence interval.

\section{RESULTS}

Among the total of 61 patients, 14 patients had PI and 47 patients had non-PI. The mean follow-up periods were 7.43 \pm 1.41 years. In the PI group, the initial symptoms were eye-related problems were dominant, such as exophthalmos or visual impairment, whereas, in the non-PI group, headache was the main symptom. The symptom of exophthalmos was notably prevalent in the PI group $(p<0.001)$ (Table 1$)$. We also investigated the surgical factors related to the presence of PI. As a result, EI score was significantly higher in the PI group while hyperostosis was concomitantly present in the PI group. Furthermore, the operation time was longer in the PI group ( $p=0.018$ ) (Table 2). The extent of resection was compared between the PI and non-PI groups. GTR was performed 35.7\% of the PI group while it was performed more $(68.1 \%)$ in nonPI group. This result suggested that total resection was less

Table 1. Clinical symptoms of patients

\begin{tabular}{|c|c|c|c|}
\hline \multirow{2}{*}{ Clinical symptom } & \multicolumn{2}{|c|}{ Periorbital invasion } & \multirow{2}{*}{$p$-value* } \\
\hline & Yes $(n=14)$ & No $(n=47)$ & \\
\hline Headache & $4(28.6)$ & $17(36.1)$ & 0.181 \\
\hline Exophthalmos & $6(42.9)$ & $0(0.0)$ & $<0.001$ \\
\hline Diplopia, visual impairment & $4(28.6)$ & $8(17.0)$ & 0.275 \\
\hline Seizure & $0(0.0)$ & $5(10.6)$ & 0.258 \\
\hline Dizziness & $0(0.0)$ & $2(4.3)$ & 0.591 \\
\hline Incidental finding & $2(14.3)$ & $9(19.1)$ & 0.512 \\
\hline Others (e.g., hand tremor, general weakness, confusion) & $3(21.4)$ & $10(21.2)$ & 0.626 \\
\hline
\end{tabular}

Values are presented as number (\%). ${ }^{*}$ Chi-square 
Table 2. Relationship between periorbital invasion and various surgery-related factors

\begin{tabular}{|c|c|c|c|}
\hline \multirow{2}{*}{ Surgical factor } & \multicolumn{2}{|c|}{ Periorbital invasion } & \multirow{2}{*}{$p$-value* } \\
\hline & Yes $(n=14)$ & No $(n=47)$ & \\
\hline Operation time (hours) & $8.63 \pm 2.91$ & $6.26 \pm 3.25$ & 0.018 \\
\hline Exophthalmos index & $1.37 \pm 0.24$ & $1.00 \pm 0.01$ & $<0.001$ \\
\hline Tumor size $(\mathrm{cm})$ & $4.72 \pm 1.68$ & $4.10 \pm 1.55$ & 0.206 \\
\hline Intra-operative bleeding (mL) & $972 \pm 614$ & $950 \pm 729$ & 0.939 \\
\hline Presence of hyperostosis & $12(85.7)$ & $2(14.3)$ & $<0.001$ \\
\hline Extent of resection & & & 0.032 \\
\hline Gross total resection $(n=37)$ & $5(35.7)$ & $32(68.1)$ & \\
\hline Subtotal resection $(n=24)$ & $9(64.3)$ & 15 (31.9) & \\
\hline
\end{tabular}

Values are presented as mean \pm standard deviation or number (\%). *Chi-square, Independent t-test

Table 3. Relationship between recurrence rates and surgical factors

\begin{tabular}{|c|c|c|c|c|c|c|}
\hline & \multicolumn{6}{|c|}{ Presence of recurrences } \\
\hline & \multicolumn{3}{|c|}{ Univariate analysis } & \multicolumn{3}{|c|}{ Multivariate analysis } \\
\hline & $\begin{array}{c}\text { Recurrence } \\
(n=11)\end{array}$ & $\begin{array}{l}\text { No recurrence } \\
\quad(n=50)\end{array}$ & $p$-value* & OR & $95 \% \mathrm{Cl}$ & $p$-value ${ }^{\dagger}$ \\
\hline Age (years) & $40.0 \pm 9.5$ & $54.6 \pm 11.4$ & 0.018 & 0.961 & $0.89-1.04$ & 0.304 \\
\hline Gender, M : F & $4: 7$ & $10: 40$ & 0.215 & 0.449 & $0.21-9.79$ & 0.610 \\
\hline Tumor size (cm) & $5.31 \pm 1.92$ & $4.01 \pm 1.42$ & 0.013 & 1.947 & $0.77-6.03$ & 0.147 \\
\hline Pre-operative exophthalmos index & $1.28 \pm 0.33$ & $1.04 \pm 0.11$ & 0.034 & 0.084 & $0.03-902.28$ & 0.516 \\
\hline Presence of periorbital invasion & & & 0.002 & 2.126 & $0.02-224.87$ & 0.751 \\
\hline Yes $(n=14)$ & $7(50.0)$ & $7(50.0)$ & & & & \\
\hline No $(n=47)$ & $4(8.5)$ & $43(91.5)$ & & & & \\
\hline Presence of hyperostosis & & & 0.003 & 0.084 & $0.03-2.54$ & 0.154 \\
\hline Yes $(n=15)$ & $7(53.3)$ & $8(46.7)$ & & & & \\
\hline No $(n=46)$ & $4(8.7)$ & $42(91.3)$ & & & & \\
\hline Extent of resection & & & 0.002 & 0.082 & $0.05-1.26$ & 0.043 \\
\hline GTR $(n=37)$ & $2(5.4)$ & 35 (94.6) & & & & \\
\hline $\operatorname{STR}(n=24)$ & $9(37.5)$ & $15(62.5)$ & & & & \\
\hline WHO grade & & & 0.630 & 0.683 & $0.01-35.99$ & 0.851 \\
\hline I $(n=54)$ & $10(18.5)$ & $44(81.5)$ & & & & \\
\hline II $(n=7)$ & $1(14.3)$ & $6(85.7)$ & & & & \\
\hline Optic apparatus invasion & & & 0.020 & 1.662 & $0.10-28.43$ & 0.725 \\
\hline Yes $(n=14)$ & $7(50.0)$ & $7(50.0)$ & & & & \\
\hline No $(n=47)$ & $4(8.5)$ & $43(91.5)$ & & & & \\
\hline Major vessel invasion & & & 0.042 & 1.009 & $0.50-20.07$ & 0.995 \\
\hline Yes $(n=33)$ & $9(27.3)$ & $24(72.7)$ & & & & \\
\hline No $(n=28)$ & $2(7.1)$ & $26(92.9)$ & & & & \\
\hline Cavernous sinus invasion & & & 0.014 & 1.849 & $0.11-31.53$ & 0.671 \\
\hline Yes $(n=23)$ & $8(34.8)$ & $15(62.2)$ & & & & \\
\hline No $(n=38)$ & $3(7.9)$ & 35 (92.1) & & & & \\
\hline
\end{tabular}

Values are presented as mean \pm standard deviation or number (\%) unless otherwise indicated. *Univariate analysis : chi-square test, independent t-test. ${ }^{\dagger}$ Multivariate analysis : logistic regression analysis. OR : odds ratio, $\mathrm{Cl}$ : confidence interval, $\mathrm{M}$ : male, F : female, GTR : gross total resection, STR : subtotal resection, WHO : World Health Organization 
performed in the PI group ( $p=0.032)$. Recurrence of tumor was noted in 11 cases in this study (i.e., seven cases from PI and four cases from non-PI groups). The mean recurrencefree interval was $41.65 \pm 26.7$ month. However, there were no statistical differences in the recurrence-free intervals when the data were analyzed based on the presence of PI (PI, 40.5 \pm 24.3 months; non-PI, $42.3 \pm 29.9$ months; $p=0.92$ ), extent of resection (GTR, 52.7 \pm 2.84 months; STR, 39.1 \pm 29.3 months; $p=0.21$ ), and presence of hyperostosis (hyperostosis, $40.1 \pm 24.3$ months; non-hyperostosis, $41.3 \pm 27.9$ months; $p=0.92$ ). Ac- cording to the univariate analysis, age, the presence of hyperostosis, EI score, the presence of PI, extent of resection, invasion of major vessel, optic apparatus, cavernous sinus, and tumor size were significantly correlated with the rates of recurrence $(p<0.05)$ (Table 3). However, in the multivariate analysis, only the extent of resection showed a statistical significance in affecting the rates of recurrence of tumor ( $p=0.043$ ) (Table 3).

The mean pre-operative EI score of PI group was 1.37 while the mean post-operative EI score was 1.12. The degree of ex-

Table 4. Relationship between complication rates and surgical factors

\begin{tabular}{|c|c|c|c|c|c|c|}
\hline & \multicolumn{6}{|c|}{ Complications } \\
\hline & \multicolumn{3}{|c|}{ Univariate analysis } & \multicolumn{3}{|c|}{ Multivariate analysis } \\
\hline & $\begin{array}{l}\text { Complications } \\
\qquad(n=20)\end{array}$ & $\begin{array}{l}\text { No complications } \\
\qquad(n=41)\end{array}$ & $p$-value* & OR & $95 \% \mathrm{Cl}$ & $p$-value ${ }^{\dagger}$ \\
\hline Age (years) & $47.9 \pm 13.0$ & $51.76 \pm 12.9$ & 0.288 & 0.977 & $0.92-1.03$ & 0.444 \\
\hline Gender, M : F & $5: 15$ & $9: 42$ & 0.515 & 0.192 & $0.03-1.49$ & 0.158 \\
\hline Tumor size (cm) & $5.2 \pm 1.6$ & $3.7 \pm 1.3$ & 0.001 & 2.602 & $1.35-5.00$ & 0.017 \\
\hline Pre-operative exophthalmos index & $1.13 \pm 0.31$ & $1.07 \pm 0.12$ & 0.270 & 43.27 & $0.09-214.20$ & 0.069 \\
\hline Presence of periorbital invasion & & & 0.515 & 18.57 & $0.54-634.10$ & 0.093 \\
\hline Yes $(n=14)$ & $5(35.7)$ & $9(25.0)$ & & & & \\
\hline No $(n=47)$ & $15(31.9)$ & $32(68.1)$ & & & & \\
\hline Presence of hyperostosis & & & 0.597 & 0.489 & $0.05-4.89$ & 0.435 \\
\hline Yes $(n=15)$ & $5(33.3)$ & $10(66.7)$ & & & & \\
\hline No $(n=46)$ & $15(32.6)$ & $31(67.4)$ & & & & \\
\hline Extent of resection & & & 0.071 & 0.316 & $0.74-1.34$ & 0.884 \\
\hline GTR $(n=37)$ & $9(24.3)$ & $28(75.7)$ & & & & \\
\hline $\operatorname{STR}(n=24)$ & $11(45.8)$ & $13(54.2)$ & & & & \\
\hline WHO grade & & & 0.416 & 0.463 & $0.04-6.10$ & 0.558 \\
\hline I $(n=54)$ & $17(31.5)$ & $37(68.5)$ & & & & \\
\hline$\|(n=7)$ & $3(42.9)$ & $4(57.1)$ & & & & \\
\hline Optic apparatus invasion & & & 0.032 & 0.393 & $0.20-7.63$ & 0.567 \\
\hline Yes $(n=14)$ & $8(57.1)$ & $6(42.9)$ & & & & \\
\hline No $(n=47)$ & $12(25.5)$ & $35(74.5)$ & & & & \\
\hline Major vessel invasion & & & 0.179 & 3.419 & $0.55-21.28$ & 0.188 \\
\hline Yes $(n=33)$ & $13(39.4)$ & $20(60.6)$ & & & & \\
\hline No $(n=28)$ & $7(25.0)$ & $21(75.0)$ & & & & \\
\hline Cavernous sinus invasion & & & 0.001 & 0.180 & $0.02-1.36$ & 0.096 \\
\hline Yes $(n=23)$ & $14(60.9)$ & $9(39.1)$ & & & & \\
\hline No $(n=38)$ & $6(15.8)$ & $32(84.2)$ & & & & \\
\hline
\end{tabular}

Values are presented as mean \pm standard deviation or number (\%) unless otherwise indicated. ${ }^{*}$ Univariate analysis : chi-square test, independent t-test. ${ }^{\dagger}$ Multivariate analysis : logistic regression analysis. OR : odds ratio, $\mathrm{Cl}$ : confidence interval, $\mathrm{M}$ : male, F : female, GTR : gross total resection, STR : subtotal resection, WHO : World Health Organization 
ophthalmos was clearly reduced after the removal of tumor mass. Specifically, in the PI group, the post-operative EI score was decreased by 0.24 . However, there was no statistically significant difference in the pre-operative and post-operative EI scores between the GTR and STR groups. This signifies that, regardless of the extents of tumor resection, debulking act of tumor mass clearly relieved the symptoms of exophthalmos.

We also analyzed the complication rates based on the presence of PI. Early complications were consisted of cranial nerve palsy $(n=14)$, infarction $(n=3)$, infection $(n=1)$, diplopia $(n=3)$, changes in facial sensation $(n=6)$, and other symptoms $(n=3)$. Late complications included the following symptoms : cranial nerve palsy $(n=14)$, infarction $(n=3)$, exposure of fixation plates $(n=1)$, and changes in facial sensation $(n=2)$. We performed the statistical analysis of various parameters focused on the late complications. According to the univariate analysis, the tumor size, the presence of hyperostosis, EI score, the presence of PI, extent of resection, invasion of major vessel, optic apparatus, and cavernous sinus were significantly correlated with the rates of recurrence $(p<0.05)$. As a result, the rates late complication rates were neither significantly different between PI and non-PI group $(p>0.05)$ nor statistically significant between GTR and STR groups $(p>0.05)$ (Table 4$)$.

\section{DISCUSSION}

This study investigated in detail about the importance of GTR in treating sphenoid wing meningioma with PI. Sphenoid wing meningioma accounts for approximately $18 \%$ of total intracranial meningioma ${ }^{7,19)}$. The nature of tumor often involves the periorbital tissue and bones because of its characteristic anatomical location in the sphenoid bone. According to the study by Sughrue et al. ${ }^{18)}$, when sphenoid wing meningioma protruded to the medial side, the rate of optic canal invasion was $50 \%$ accompanied by ptosis or visual disturbance. In the case of lateral extension of sphenoid wing meningioma, surgical resection is relatively simple as in the cases of convexity meningioma. However, when sphenoid wing meningioma was growing into the medial area, surgical difficulties are inevitable due to the invasion of orbital components of the tumor, which may lead to deficits of cranial nerve functions. Therefore, the surgical goals of treating sphenoid wing meningioma with PI in the prior studies mentioned controversy in many cases because of their concerns about the surgical complications. Saeed et al. ${ }^{14)}$ emphasized the strategy of "wait and see" because of its slowing growth rate $0.3 \mathrm{~cm}^{3} /$ year. Ringel et al. ${ }^{13)}$ reported that the main goal of treatment should be the relief of symptoms rather than radical resection. On the other hand, Couldwell et al. ${ }^{3)}$ encouraged the aggressive resection of tumor mass in order to improve the symptoms such as proptosis. Bikmaz et al. ${ }^{1)}$ also supported the views of aggressive resection of this type tumor by drilling the hyperostotic sphenoid bone. The rates of GTR in spheno-orbital meningioma were reported variously about $10 \%$ to $83 \%$ from the previous studies $^{2,12,16)}$. To date, several studies of surgical technique or outcomes of sphenoid wing meningioma have been reported, but the reports on the surgical outcomes according to the presence or absence of PI in sphenoid wing meningioma were few to our best knowledge. Thus, we hypothesized that, even with PI, GTR of sphenoid wing meningioma can significantly lower the recurrence rate and the need for post-operative radiotherapy with "acceptable" level of minimal complications and morbidities.

In this clinical study, we investigated whether the presence of PI affected the degree of surgical difficulty. The criteria for surgical difficulty were defined by the following parameters : operation time, bleeding amount during the operation, and the rates of GTR. As a result, longer operation time was taken in the cases with the PI while the number of cases with GTR was also lesser than those patients without the PI. Moreover, the rates of hyperostosis were higher in the cases with PI, and this finding showed a statistical significance. Based on this analysis, it is clear that the degree of surgical difficulties is increased if the sphenoid wing meningioma is accompanied with the PI. We also investigated the relationship of the extent of the resection with the incidences of surgical complication or with the recurrence rates of tumor after the operation. Resultantly, the recurrence rates in the patients of PI group, who received GTR, were lower while the incidences of surgical complication between the groups of GTR and STR showed no significant difference.

Surgical resection of sphenoid wing meningioma with PI is technically demanding due to the difficult removal of hyperostosis with enough resection margin, reconstruction of bony structure and dura mater, and conservation of important anatomical structures such as optic nerve, oculomotor nerve, trigeminal nerve or internal carotid artery ${ }^{5,6,15,17)}$. The post-oper- 
ative complications of our study included blindness, limitation of extra-ocular movement, facial numbness, leakage of cerebrospinal fluid, and the exposure of cranial fixation plate with wound infection. These were consistent with previous studies $^{9,20)}$. Moreover, the number of cases of GTR in the PI group was lower than the non-PI group. However, even with these potential risks, we suggest that the surgical strategy of sphenoid wing meningioma with PI should comprise a maximal total resection of the tumor mass. Our results clearly showed that the recurrence rates of sphenoid wing meningioma with PI after GTR are as low as those of sphenoid wing meningioma without PI. This carefully implicates that the GTR in sphenoid wing meningioma with PI can significantly reduce the recurrence rates of the high grade sphenoid wing meningioma with better clinical outcome.

\section{Limitations}

The limitation of our study is that this is a retrospective investigation in a single institution. Our institution has a large skull base surgery center, and the surgical data were obtained from a single neurosurgeon with extensive experience and expertise in skull base tumors. The surgical goal of this type tumor has to be flexible as the medical conditions of the patients with this kind of tumors are diverse. Surgical difficulties must be considered differently in the individual cases. Hence, the treatment regimen must be tailored to fit the individual patients based on the various clinical situations. Nevertheless, this study has proven, in part, that the rates of post-operative tumor recurrences can be markedly reduced in the cases of sphenoid wing meningioma with PI when the GTR was conducted aggressively. There is no doubt that this is closely related to the long-term clinical outcome of the patients with this specific types of skull base tumor.

\section{CONCLUSION}

We hereby report our neurosurgical experiences in the cases of sphenoid wing meningioma with PI. According to our data, the most critical factor in determining the rate of recurrence was the extent of surgical resection. The incidences of surgical complication were not notably different between the GTR and STR of the tumor mass. The treatment option of this type of tumor is still controversial as there are many hurdles of surgi- cal difficulties present to be overcome. The acceptable level of minimal morbidity and preservation of cranial nerve functions are crucial for long-term outcomes of the patients. Nevertheless, the active consideration of GTR in sphenoid wing meningioma with PI is highly recommended for the better clinical outcomes of the patients.

\section{AUTHORS' DECLARATION}

\section{Conflicts of interest}

No potential conflict of interest relevant to this article was reported.

\section{Informed consent}

This type of study does not require informed consent.

\section{Author contributions}

Conceptualization : CKH, JO; Data curation : JO, GOP; Formal analysis : HHP; Methodology : JY; Project administration : GOP; Visualization : GOP, JO; Writing - original draft : GOP; Writing - review \& editing : GOP, JO

\section{Data sharing}

None

\section{Preprint}

None

\section{ORCID}

$\begin{array}{ll}\text { Ga-On Park } & \text { https://orcid.org/0000-0003-3593-5458 } \\ \text { Hyun Ho Park } & \text { https://orcid.org/0000-0002-2526-9693 } \\ \text { Jihwan Yoo } & \text { https://orcid.org/0000-0001-8746-1245 } \\ \text { Chang-Ki Hong } & \text { https://orcid.org/0000-0002-2761-0373 } \\ \text { Jiwoong Oh } & \text { https://orcid.org/0000-0001-6065-4821 }\end{array}$

\section{References}

1. Bikmaz K, Mrak R, Al-Mefty 0 : Management of bone-invasive, hyperostotic sphenoid wing meningiomas. J Neurosurg 107 : 905-912, 2007

2. Boari N, Gagliardi F, Spina A, Bailo M, Franzin A, Mortini P : Manage- 
ment of spheno-orbital en plaque meningiomas: clinical outcome in a consecutive series of 40 patients. Br J Neurosurg 27 : 84-90, 2013

3. Couldwell WT, Kan P, Liu JK, Apfelbaum RI : Decompression of cavernous sinus meningioma for preservation and improvement of cranial nerve function. Technical note. J Neurosurg 105 : 148-152, 2006

4. Elborady MA, Nazim WM : Spheno-orbital meningiomas: surgical techniques and results. Egypt J Neurol Psychiatry Neurosurg 57 : 1-9, 2021

5. Forster MT, Daneshvar K, Senft C, Seifert V, Marquardt G : Sphenoorbital meningiomas: surgical management and outcome. Neurol Res 36 : 695-700, 2014

6. Gonen L, Nov E, Shimony N, Shofty B, Margalit N : Sphenoorbital meningioma: surgical series and design of an intraoperative management algorithm. Neurosurg Rev 41 : 291-301, 2018

7. Honig S, Trantakis C, Frerich B, Sterker I, Kortmann RD, Meixensberger $\mathrm{J}$ : Meningiomas involving the sphenoid wing outcome after microsurgical treatment--a clinical review of 73 cases. Cent Eur Neurosurg 71 : 189-198, 2010

8. Kiyofuji S, Casabella AM, Graffeo CS, Perry A, Garrity JA, Link MJ : Sphenoorbital meningioma: a unique skull base tumor. Surgical technique and results. J Neurosurg 133 : 1044-1051, 2020

9. Li Y, Shi JT, An YZ, Zhang TM, Fu JD, Zhang JL, et al. : Sphenoid wing meningioma en plaque: report of 37 cases. Chin Med J (Engl) 122 : 2423-2427, 2009

10. Mariniello G, Maiuri F, Strianese D, Donzelli R, Iuliano A, Tranfa F, et al. : Spheno-orbital meningiomas: surgical approaches and outcome according to the intraorbital tumor extent. Zentralbl Neurochir 69 : 175181,2008

11. Masalha W, Heiland DH, Steiert C, Krüger MT, Schnell D, Scheiwe C, et al. : Progression-free survival, prognostic factors, and surgical outcome of spheno-orbital meningiomas. Front Oncol $11: 672228,2021$

12. Menon S, Sandesh O, Anand D, Menon G : Spheno-orbital meningiomas: optimizing visual outcome. J Neurosci Rural Pract 11 : 385394, 2020

13. Ringel F, Cedzich C, Schramm J : Microsurgical technique and results of a series of 63 spheno-orbital meningiomas. Neurosurgery 60(4 Suppl 2) : 214-221; discussion 221-222, 2007

14. Saeed P, van Furth WR, Tanck M, Kooremans F, Freling N, Streekstra Gl, et al. : Natural history of spheno-orbital meningiomas. Acta Neurochir (Wien) $153:$ 395-402, 2011

15. Samadian M, Sharifi G, Mousavinejad SA, Amin AA, Ebrahimzadeh K, Tavassol HH, et al. : Surgical outcomes of sphenoorbital en plaque meningioma: a 10-year experience in 57 consecutive cases. World Neurosurg $144:$ e 576 -e581, 2020

16. Scarone $P$, Leclerq $D$, Héran $F$, Robert $G$ : Long-term results with exophthalmos in a surgical series of 30 sphenoorbital meningiomas. Clinical article. J Neurosurg 111 : 1069-1077, 2009

17. Shrivastava RK, Sen C, Costantino PD, Della Rocca R : Sphenoorbital meningiomas: surgical limitations and lessons learned in their long-term management. J Neurosurg 103 : 491-497, 2005

18. Sughrue ME, Rutkowski MJ, Chen CJ, Shangari G, Kane AJ, Parsa AT, et al. : Modern surgical outcomes following surgery for sphenoid wing meningiomas. J Neurosurg 119 : 86-93, 2013

19. Talacchi A, Hasanbelliu A, D'Amico A, Regge Gianas N, Locatelli F, Pasqualin $A$, et al. : Long-term follow-up after surgical removal of meningioma of the inner third of the sphenoidal wing: outcome determinants and different strategies. Neurosurg Rev 43 : 109-117, 2020

20. Xu G, Du JX, Ye M, Zhao RL, Ling F : Analysis of the causes of surgical complications of medial sphenoidal ridge meningioma. Zhonghua $\mathrm{Yi}$ Xue Za Zhi 86 : 632-635, 2006 